\title{
Studi Konduktivitas Solid Polymer Electrolyte (SPE) PEO (Poly Ethylene Oxide) dengan Fly ash dari PT. Tjiwi Kimia Sidoarjo
}

\author{
Arlita Sandya Satya Wardhani, Yatim Lailun Ni'mah, dan Harmami \\ Departemen Kimia, Fakultas Matematika dan Ilmu Pengetahuan Alam, Institut Teknologi Sepuluh Nopember (ITS) \\ e-mail: yatimnikmah@gmail.com
}

\begin{abstract}
Abstrak-Pengaruh penambahan abu layang pada Solid Polymer Electrolyte (SPE) PEO (Poly Ethylene Oxide) dan garam $\mathrm{LiClO}_{4}$ (Lithium Perchlorate) telah diteliti. Kristalinitas PEO berkurang

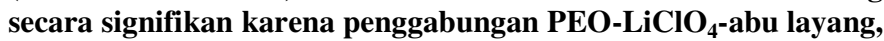
yang diuji menggunakan $X$-Ray Diffraction (XRD). Interaksi ionpolimer, khususnya interaksi antara kation $\mathrm{LiClO}_{4}$-abu layang dengan atom eter oksigen dari PEO, telah dibuktikan dengan FTIR. Penambahan abu layang 5\% meningkatkan nilai konduktivitas ionik SPE yaitu $1,730 \times 10^{-4} \mathrm{~S} / \mathrm{cm}$ pada suhu $60^{\circ} \mathrm{C}$. Sedangkan nilai konduktivitas ionik PEO murni sebesar 7,859 $\mathrm{x}$

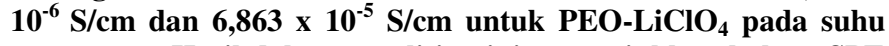
yang sama. Hasil dalam penelitian ini menunjukkan bahwa SPE PEO dengan penambahan $\mathrm{LiClO}_{4}$ dan abu layang merupakan salah satu material elektrolit untuk baterai ion lithium.
\end{abstract}

Kata Kunci-Solid Polymer Electrolyte, Baterai ion lithium, Konduktivitas ionic, Pengisi, Abu layang.

\section{PENDAHULUAN}

B ATERAI ion litium isi ulang (LIB) merupakan salah satu teknologi penyimpanan energi yang paling penting dan telah menjadi bagian yang tidak dapat terpisahkan dari kehidupan sehari-hari [1]. Baterai ion litium merupakan salah satu baterai yang paling dibutuhkan, karena dapat di charge ulang, ringan, tahan lama, aman penggunaannya dan mudah diolah dalam berbagai bentuk [2].

Salah satu insiden terbaru dalam penggunaan baterai ion litium yaitu kebakaran yang terjadi pada mobil listrik unit Tesla Model S dan pesawat Dreamliner Boeing 787. Sehingga dalam baterai lithium isi ulang kebijakan safety merupakan hal terpenting [3].

Solid Polymer Electrolyte (SPE) dianggap sebagai salah satu solusi yang layak untuk menjamin keamanan dalam baterai litium isi ulang daya tinggi [4]. SPE memiliki beberapa keunggulan dibandingkan dengan elektrolit cair seperti tidak volatil, tidak mudah terbakar, mudah untuk diproses, stabilitas kimia dan elektrokimia yang baik [4][5][6][7].

Penelitian mengenai penambahan filler (pengisi) telah banyak dilakukan. Penelitian sebelumnya oleh Song dkk [8] dihasilkan konduktivitas sebesar $9,6 \times 10^{-4} \mathrm{~S} / \mathrm{cm}$ dengan adanya penambahan pengisi $\mathrm{SiO}_{2}$ sebanyak $5 \%$ pada $\mathrm{PEO}-\mathrm{AlCl}_{3}$. Sementara Fullerton dkk [9] melaporkan dalam penelitiannya bahwa konduktivitas tertinggi diperoleh dengan penambahan $\mathrm{Al}_{2} \mathrm{O}_{3}$ sebanyak 5\% pada PEO- $\mathrm{LiClO}_{4}$.

Fly ash (abu layang) dapat digunakan sebagai pengisi yang ditambahkan pada matriks polimer PEO dengan kompleks garam $\mathrm{LiClO}_{4}$. Abu layang adalah abu sisa pembakaran batu bara yang dipakai dalam banyak industri. Selama ini abu layang tidak dimanfaatkan dan dibuang begitu saja, sehingga memiliki potensi mencemari lingkungan. Abu layang terdiri dari bahan anorganik $\left(\mathrm{SiO}_{2}, \mathrm{Al}_{2} \mathrm{O}_{3}, \mathrm{Fe}_{2} \mathrm{O}_{3}\right.$, dan $\left.\mathrm{CaO}\right)$ yang terdapat di dalam batu bara yang telah mengalami fusi selama pembakarannya [10].

Abu layang akan digunakan untuk menggantikan peran $\mathrm{SiO}_{2}$ dan $\mathrm{Al}_{2} \mathrm{O}_{3}$ sebagai pengisi anorganik. Pada penelitian ini abu layang yang digunakan berasal dari PT. TJIWI KIMIA Sidoarjo dengan konsentrasi yang ditambahkan sebanyak 5\% seperti optimasi yang pernah dilakukan pada penelitian diatas.

\section{METODE PENELITIAN}

\section{A. Alat dan Bahan}

Peralatan yang digunakan dalam penelitian ini adalah gelas beaker, tabung reaksi, pipet ukur, pro pipet, spatula, kaca arloji, thermometer digital stick, magnetic stirrer, teflon petri dish, neraca analitik (Ohaus PA214), oven (Freas 605), XRD (Phillips X'Pert MPD), FTIR (Shimadzu), dan spektroskopi AC impedansi (Autolab ECl10M). Sedangkan bahan yang digunakan dalam penelitian ini adalah PEO) $\mathrm{Mw}=6 \times 10^{5} \mathrm{~g}$ $\mathrm{mol}^{-1}$ (Sigma Aldrich), garam $\mathrm{LiClO}_{4}$ (Sigma Aldrich, 99,9\%), asetonitril (Emsure Merck KGaA) dibeli dari Germany, dan abu layang dari PT.Tjiwi Kimia diambil dari kota Sidoarjo Indonesia.

\section{B. Sintesis Solid Polymer Electrolyte (SPE)}

SPE dibuat dengan tiga variasi yaitu PEO $100 \%$, PEO$\mathrm{LiClO}_{4} 10 \%$, dan PEO-LiClO 4 10\%-abu layang 5\%, dilarutkan dalam asetonitril yang digunakan sebagai solvent untuk preparasi dari elektrolit polimer sebanyak $8 \mathrm{~mL}$ dan diaduk selama 6 jam untuk mendapat larutan homogen kental pada suhu $55{ }^{\circ} \mathrm{C}$. Larutan tersebut kemudian dituangkan kedalam sebuah teflon petri dish (diameter $2 \mathrm{~cm}$ ). Kemudian SPE dikeringkan di dalam oven pada suhu $55{ }^{\circ} \mathrm{C}$ selama 6 jam. Proses sintesis SPE dan skema interaksi antara PEO, $\mathrm{LiClO}_{4}$ dan abu layang ditampilkan dalam Gambar 3.1

\section{Karakterisasi FTIR}

Sampel digerus bersama-sama dengan suatu halida anorganik yang memiliki ikatan ionik sehingga tidak akan menyerap sinar inframerah karena tidak ada vibrasi molekul di dalamnya. Pada penelitian ini akan menggunakan senyawa $\mathrm{KBr}$. Setelah digerus hingga bercampur sempurna, kemudian 
dipres pada tekanan 8 hingga 20 ton per satuan luas menjadi cakram tipis atau pelet. Kemudian pelet tersebut dimasukkan ke dalam susunan alat dan kemudian siap ditembak oleh sinar inframerah. FTIR menggunakan spectrometer Nicolet 380 FTIR di wilayah $4000-400 \mathrm{~cm}^{-1}$ pada resolusi dari $1 \mathrm{~cm}^{-1}$.

\section{Karakterisasi Elektrokimia}

Impedansi dan konduktivitas dari sampel ditentukan dengan Autolab ECl10M. Film SPE diselipkan diantara dua elektroda Stainless Steel (SS) (diameter $2 \mathrm{~cm}$ ) dalam sebuah koin sel. Ketebalan setiap sampel diukur dengan menggunakan alat ukur jangka sorong. Pengukuran impedansi dilakukan dalam rentang frekuensi $1 \mathrm{~Hz}$ sampai $1 \mathrm{MHz}$ sampel $1 \mathrm{~Hz}$ dengan kecepatan $10 \mathrm{mVs}^{-1}$. Konduktivitas dianalisis dengan memvariasikan suhu 313 - $363 \mathrm{~K}$ (ditahan setiap perubahan $10{ }^{\circ} \mathrm{C}$ selama $\left.1 \mathrm{jam}\right)$.

Konduktivitas ionik dari berbagai polimer elektrolit telah ditentukan menggunakan persamaan:

$$
\sigma=\frac{t}{(A \times R b)}
$$

Dimana $\sigma$ adalah konduktivitas dihitung dalam $\mathrm{S} / \mathrm{cm}, \mathrm{t}$ adalah ketebalan film, A adalah luas permukaan film, dan $\mathrm{Rb}$ adalah resistansi film dalam satuan ohm.

\section{HASIL DAN DISKUSI}

\section{A. Hasil Sintesis Solid Polymer Electrolyte (SPE)}

SPE yang disentesis dalam penelitian ini merupakan gabungan PEO, dengan garam $\mathrm{LiClO}_{4}$ dan pengisi abu layang. Abu layang yang dipakai berasal dari PT. TJIWI KIMIA Sidoarjo Indonesia. Sintesis ini dilakukan dengan mengadaptasi prosedur sintesis $\mathrm{PEO} / \mathrm{LiClO}_{4} / \mathrm{TiO}_{2}$ oleh $\mathrm{Lin}$ dkk, [11] dan PEO/ $\mathrm{NaClO}_{4} / \mathrm{TiO}_{2}$ oleh Ni'mah dkk [12]. Modifikasi dilakukan dengan mengganti pengisi $\mathrm{TiO}_{2} 5 \%$ dengan abu layang sebanyak $5 \%$.

Dilakukan 3 variasi yaitu PEO murni, PEO - $\mathrm{LiClO}_{4} 10 \%$, dan PEO - $\mathrm{LiClO}_{4}$ - abu layang 5\% dilarutkan dalam asetonitril yang digunakan sebagai solvent untuk preparasi dari elektrolit polimer sebanyak $8 \mathrm{~mL}$ dan diaduk selama 6 jam untuk mendapat larutan homogen kental pada suhu $55^{\circ} \mathrm{C}$. Lalu sampel didiamkan selama semalam agar gelembung menghilang dari sampel dan dalam keadaan tertutup.

Campuran tersebut kemudian dituangkan kedalam sebuah teflon petri dish (diameter $2 \mathrm{~cm}$ ) secara perlahan lahan agar tidak terdapat gelembung saat penuangan. Kemudian SPE dikeringkan di dalam oven pada suhu $55{ }^{\circ} \mathrm{C}$ selama 6 jam untuk menguapkan larutan asetonitril. Hasil oven berbentuk membran dengan ketebalan 0,025. Diamkan sebentar lalu diambil membran dengan piset agar tidak rusak.

Dapat dilihat pada Gambar 4.1 hasil membran SPE dengan variasi berbeda. SPE PEO murni transparan dan agak keras, sedangkan saat ditambahkan garam $\mathrm{LiClO}_{4}$ membram buram atau berwarna putih dan lunak dan saat penambahan abu layang berwarna coklat karena penambahan abu layang dan lunak.

\section{B. Karakterisasi FTIR}

Karakterisasi FTIR digunakan untuk memeriksa kemungkinan interaksi yang terjadi antara ion dan polimer serta perubahan konformasi pada sejumlah besar polimer.
Perubahan konformasi ini disebabkan karena penambahan garam $\mathrm{LiClO}_{4}$ dan penambahan pengisi abu layang $5 \%$. Gambar 3.2 menunjukkan spektra FTIR hasil sintesis.

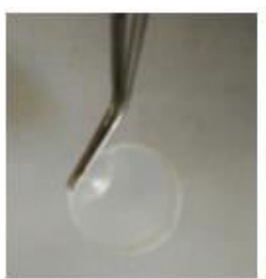

(a)

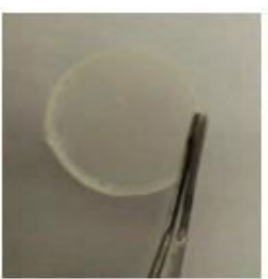

(b)

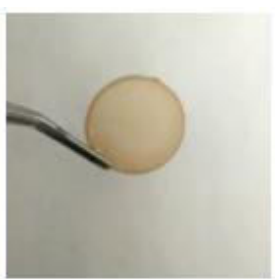

(c)
Gambar 1. Membran SPE berdasarkan PEO dengan variasi penambahan garam $\mathrm{LiClO}_{4}$ dan penambahan abu layang. (a) PEO murni, (b) PEO - $\mathrm{LiClO}_{4}$, (c) PEO - $\mathrm{LiClO}_{4}-$ abu laying $5 \%$

Mode vibrasi yang paling utama dan bilangan gelombang yang ditunjukkan oleh PEO murni adalah vibrasi kibas (wagging) $\mathrm{CH}_{2}$ pada daerah serapan $2918 \mathrm{~cm}^{-1}, \mathrm{CH}_{2}$ lentur pada daerah serapan 1458 dan $1350 \mathrm{~cm}^{-1}, \mathrm{CH}_{2}$ simetric pada daerah serapan $958 \mathrm{~cm}^{-1}$ dan $\mathrm{CH}_{2}$ asimetric pada daerah serapan $844 \mathrm{~cm}^{-1}$. Pada pita serapan tersebut PEO yang ditambahkan garam elektrolit memiliki intensitas yang lebih rendah. Hasil ini membuktikan bahwa interaksi yang terjadi antara oksigen PEO dan kation $\left(\mathrm{Li}^{+}\right.$dan $\left.\mathrm{ClO}_{4}{ }^{-}\right)$terbentuk sesuai dengan hasil penelitan oleh peneliti- peneliti sebelumnya.

Peregangan C-O-C ditemukan pada daerah serapan 1103 $\mathrm{cm}^{-}{ }^{1}$. Saat penambahan pengisi abu layang intensitas menurun, dan terbukti bahwa kompleks $\mathrm{Li}^{+}$- PEO terbentuk. Ditemukan puncak baru pada daerah serapan 630 dan $627 \mathrm{~cm}^{-1}$ yang diindikasikan sebagai pita serapan $\mathrm{ClO}_{4}$. Puncak tersebut hanya teramati pada PEO - $\mathrm{LiClO}_{4}$ dan $\mathrm{PEO}-\mathrm{LiClO}_{4}-\mathrm{abu}$ layang.

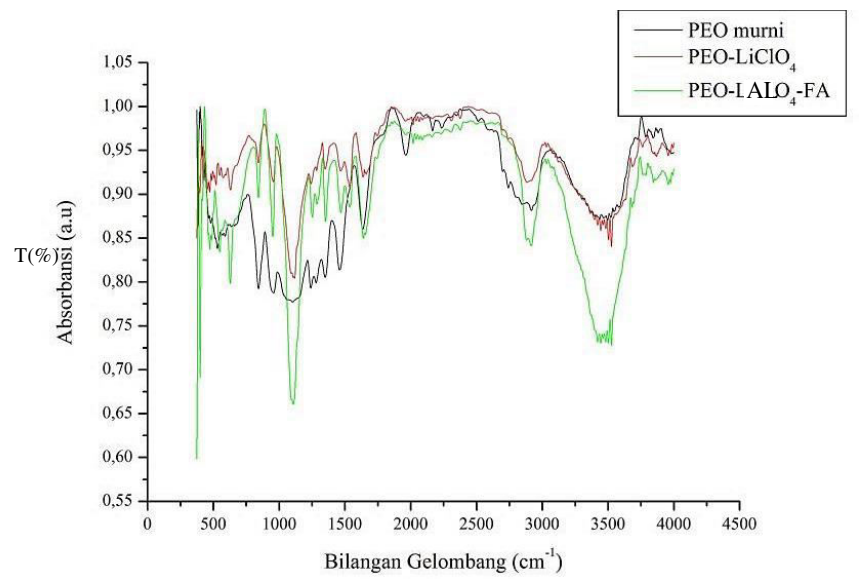

Gambar 2. Spektra FTIR pada SPE berbasis PEO dengan variasi LiClO4 dan penambahan pengisi abu layang.

\section{Karakterisasi XRD}

Karakterisasi XRD dilakukan untuk mengetahui kemungkinan perubahan sifat semi-kristal selama penambahan garam lithium $\left(\mathrm{LiClO}_{4}\right)$ dan penambahan pengisi abu layang. Pada Gambar 3.3. menunjukkan pola XRD dari PEO murni, penambahan garam $\mathrm{LiClO}_{4}$ dan penambahan pengisi abu layang. 


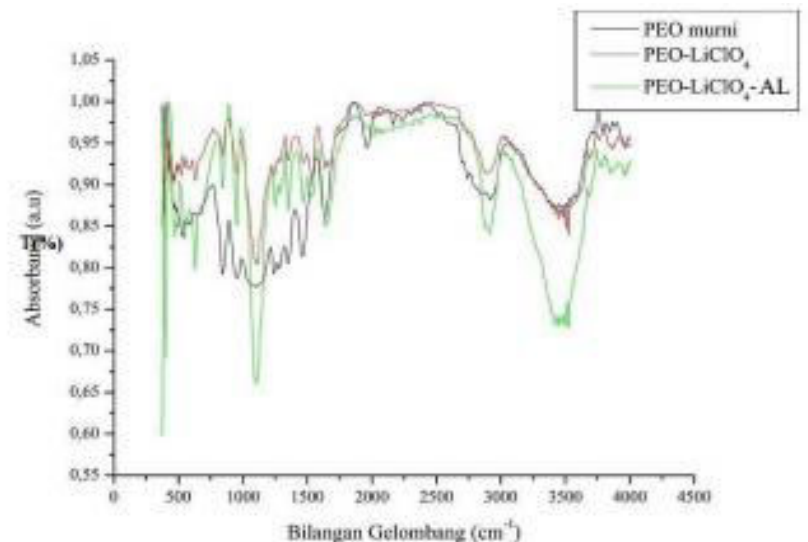

Gambar 3. Pola XRD, PEO murni dengan penambahan garam $\mathrm{LiClO} 4$ dan penambahan pengisi abu layang.

Berdasarkan hasil pola XRD, PEO murni mempunyai puncak karakteristik yang tajam pada $2 \theta=19,14^{\circ}$ dan $23,24^{\circ}$ dengan puncak-puncak dasar yang berada pada sudut $2 \theta^{\circ}$ : $14,61734^{\circ} ; 14,63405^{\circ} ; 15,05183^{\circ} ; 15,06854^{\circ} ; 22,02043^{\circ}$; $22,03714^{\circ} ; 26,95025^{\circ} ; 26,96696^{\circ}$ dan 26,98367 . Puncak karekteriktik tersebut menandakan daerah kristalin dan puncak-puncak dasar menandakan daerah amorf. Penambahan $\mathrm{LiClO}_{4}$ kedalam matrik PEO menunjukkan adanya penurunan drastis pada intensitas dan kristalinitas PEO murni. Hal ini dapat terjadi karena gangguan pada struktur semi kristalin oleh penambahan garam $\mathrm{LiClO}_{4}$. Saat penambahan pengisi abu layang, puncak XRD menunjukkan adanya penurunan itensitas yang menandakan sifat amorf.

\section{Konduktivitas Ionik}

Hubungan antara konduktivitas ionik SPE dengan suhu ditunjukkan pada Gambar 3.5. Plot impedansi yang kompleks dari membran elektrolit PEO - $\mathrm{LiClO}_{4}$ - abu layang pada suhu ruang ditunjukkan pada Gambar 3.4.

Pada kurva tersebut terlihat bahwa konduktivitas ionik meningkat secara linier dengan temperatur. Konduktivitas ionik pada seluruh sampel dihitung dengan persamaan (3.1). Resistansi bahan (ohm) didapat dari intersep semi lingkaran dengan axis real, pada daerah frekuensi $1 \mathrm{MHz}-1 \mathrm{~Hz}$. Gambar 3.4 plot impedansi (Z' vs Z') dari PEO murni dan PEO $\mathrm{LiClO}_{4}$ - abu layang $5 \%$ pada suhu $50{ }^{\circ} \mathrm{C}$. Spektra impedansi terdiri dari busur pada daerah berfrekuensi tinggi dan diikuti garis linear pada daerah frekuensi rendah. Saat penambahan garam $\mathrm{LiClO}_{4}$ dan pengisi abu layang terjadi pergeseran pada impedansi ke resistansi lebih rendah pada real axis. Dapat dilihat konduktivitas ionik pada saat PEO suhu $50{ }^{\circ} \mathrm{C}$ sebesar $7,284 \times 10^{-6}$ dan pada penambahan pengisi abu layang $5 \%$ suhu $50{ }^{\circ} \mathrm{C}$ konduktivas meningkat menjadi $1,206 \times 10^{-4}$.
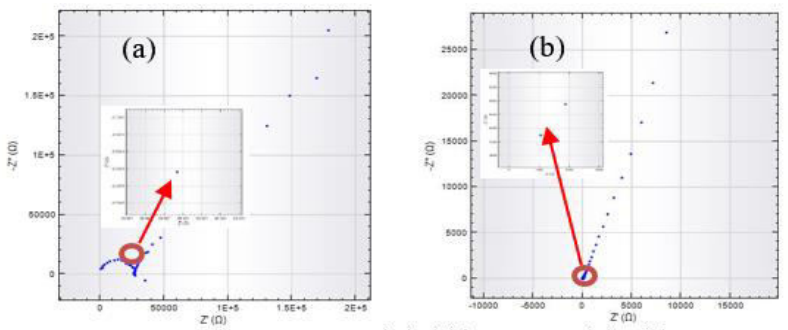

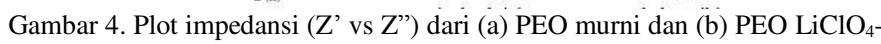
abu layang $5 \%$ pada suhu $50{ }^{\circ} \mathrm{C}$.
Dapat dilihat pada Gambar 3.5 konduktivitas naik seiring dengan penambahan suhu hal ini dinyatakan karena mobilitas $\mathrm{Li}^{+}$yang tinggi karena temperatur dinaikkan. Seperti yang terlihat pada bidang konduktivitas temperature, $\mathrm{PEO}-\mathrm{LiClO}_{4}$ abu layang menghasilkan konduktivitas ionik yang besar yaitu $1,730 \times 10^{-4}$ pada suhu $60{ }^{\circ} \mathrm{C}$ dibandingkan PEO murni dan PEO - $\mathrm{LiClO}_{4}$. Konduktivitas optimum diperoleh pada suhu 60 ${ }^{\circ} \mathrm{C}$ sesuai dengan penelitian sebelumnya oleh Lin dkk [11]. Sifat dari kenaikan konduktivitas dipengaruhi temperature dapat dipelajari dalam terminologi model volume yang kosong. Tipe ini juga dilaporkan pada sistem polimer elektrolit. Seiring kenaikan temperatur, polimer dapat menyebar dengan mudah dan menghasilkan volume yang kosong. Sehingga, semakin tinggi temperatur, semakin naik volume yang kosong. Konduktivitas yang dihasilkan mewakili seluruh pergerakan ion-ion dan polimer, ditentukan oleh volume yang kosong di sekitar rangkaian polimer. Oleh karena itu, saat temperatur meningkat maka ion molekul terlarut atau segmen polimer dapat berpindah ke volume yang kosong. Hal ini menyebabkan kenaikan pergerakan ion dan pergerakan segmen sehingga membantu transpor io

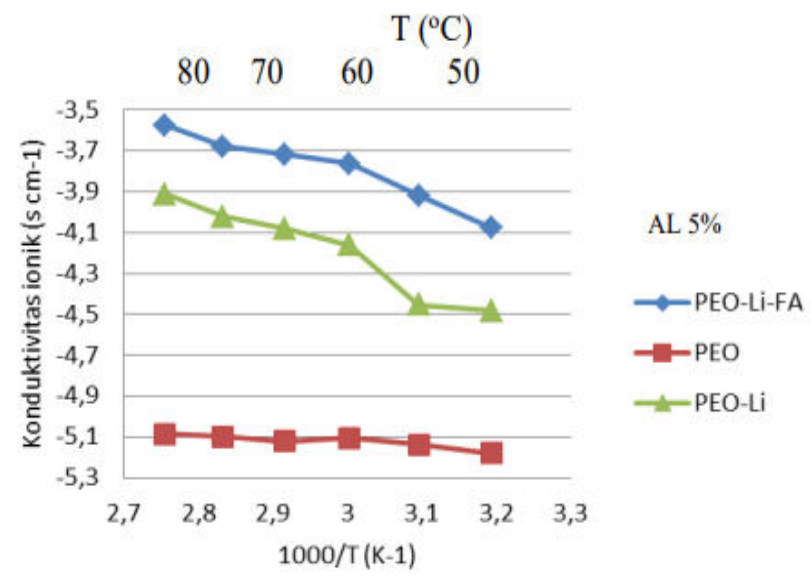

Gambar 5. Plot konduktivitas ionik vs suhu, pada SPE dengan PEO LiClO4 dan PEO - LiClO4 - abu layang.

\section{KESIMPULAN DAN SARAN}

\section{A. Kesimpulan}

Membran SPE berhasil disentesis dengan variasi PEO murni, PEO - $\mathrm{LiClO}_{4}$ dan $\mathrm{PEO}-\mathrm{LiClO}_{4}$ - abu layang 5\%. Studi XRD menunjukkan sifat amorf dari membran SPE yang menghasilkan konduktivitas ionik yang lebih besar. Karakterisasi FTIR menunjukkan interaksi yang terjadi antara ion dan polimer serta perubahan konformasi pada sejumlah besar polimer. Dari spektroskopi impedansi, telah menunjukkan bahwa konduktivitas ionik membran semakin tinggi seiring dengan penambahan suhu dan menghasilkan nilai maksimum sebesar $1,730 \times 10^{-4} \mathrm{~S} / \mathrm{cm}$ pada $60{ }^{\circ} \mathrm{C}$ untuk PEO - $\mathrm{LiClO}_{4}-$ abu layang $5 \%$ sedangkan nilai konduktivitas ionik PEO murni sebesar 7,859 × $10^{-6} \mathrm{~S} / \mathrm{cm}$ dan $6,863 \times 10^{-5}$ $\mathrm{S} / \mathrm{cm}$ untuk $\mathrm{PEO}-\mathrm{LiClO}_{4}$ pada suhu yang sama. Hasil dalam penelitian ini menunjukkan bahwa SPE PEO dengan penambahan $\mathrm{LiClO}_{4}$ dan abu layang 5\%. merupakan salah satu material elektrolit untuk baterai ion lithium. 


\section{B. Saran}

Penelitian ini dapat dikembangkan lebih lanjut mengenai sifat elektrokimia seperti charge-discharge, dan lain lain. Serta penelitian ini dapat digunakan di masyarakat untuk memanfaatkan limbah abu layang sebagai bahan pengisi anorganik baterai dengan konduktivitas tinggi.

\section{DAFTAR PUSTAKA}

[1] B. Chen, Z. Huang, X. Chen, Y. Zhao, Q. Xu, and P. Long, "A new composite solid electrolyte PEO/Li10GeP2S12/SN for all-solidstate lithium battery," Electrochim. Acta, vol. 210, pp. 905-914, 2016.

[2] B. Prihandoko, "Pemanfaatan soda lime silica dalam pembuatan komposit elektrolit baterai lithium," Universitas Indonesia, 2007.

[3] R. Khurana, J. L. Schaefer, L. A. Archer, and G. W. Coates, "Suppression of Lithium Dendrite Growth Using Cross-Linked Polyethylene / Poly (ethylene oxide) Electrolytes: A New Approach for Practical Lithium-Metal Polymer Batteries," J. Am. Chem. Soc., vol. 136, no. 20, pp. 7395-7402, 2014.

[4] J. M. Tarascon and M. Armand, "Issues and challenges facing rechargeable lithium batteries," Nature, vol. 414, pp. 359-367, 2011.

[5] B. Scrosati and J. Garche, "Lithium batteries: Status, prospects and future,” J. Power Sources, vol. 195, pp. 2419-2430, 2010.
S. J. Kwon, D. G. Kim, J. Shim, J. H. Lee, J. H. Baik, and J. C. Lee, "Preparation of organic/inorganic hybrid semi-interpenetrating network polymer electrolytes based on poly(ethylene oxide-coethylene carbonate) for all-solid-state lithium batteries at elevated temperatures," Polymer (Guildf)., vol. 55, no. 12, pp. 2799-2808, 2014.

[7] M. Grunebaum et al., "Synthesis and electrochemistry of polymer based electrolytes for lithium batteries," Prog. Solid State Chem., vol. 42, pp. 85-105, 2014.

[8] S. Song et al., "A hybrid polymer/oxide/ionic-liquid solid electrolyte for Na-metal batteries," J. Mater. Chem., vol. 5, pp. 6424-6431, 2017.

[9] S. K. Fullerton and K. M. Janna, "Structure and Mobility of PEO/LiClO4 Solid Polymer Electrolytes Filled with Al2O3 Nanoparticles,” J. Physic Chem., vol. 114, pp. 9196-9206, 2010.

[10] S. R. P. Wardani, "Pemanfaatan Limbah Batubara (Fly Ash) untuk Stabilisasi Tanah Maupun Keperluan Teknik Sipil Lainnya Dalam Mengurangi Pencemaran Lingkungan," Universitas Diponegoro, 2008.

[11] C. W. Lin a, C. L. Hung, M. Venkateswarlu, and B. J. Hwang, "Influence of $\mathrm{TiO} 2$ nano-particles on the transport properties Of composite polymer electrolyte for lithium-ion batteries," J. Power Sources, vol. 146, pp. 397-401, 2005.

[12] Y. L. Ni'mah, M. Yao Cheng, J. H. Cheng, J. Rick, and B.-J. Hwang, "Solid-state polymer nanocomposite electrolyte of $\mathrm{TiO} / \mathrm{PEO} / \mathrm{NaClO} 4$ for sodium ion batteries," J. Power Sources, vol. 278, pp. 375-381, 2015. 